\title{
A PARTICIPAÇÃO DE COOPERATIVAS NAS LICITAÇÕES DA ADMINISTRAÇÃO PÚBLICA
}

\author{
RENATO LOPES BECHO*
}

I-Introdução. II - Breves colocações sobre o princípio da igualdade. $I$ - Igualdade formal e igualdade substancial. 2 - Princípio da Igualdade. 3 - Igualdade na lei e igualdade perante a lei. 4 - Igualdade na Administração Pública. III - Igualdade na licitação. 1 - Princípios regedores da licitação. 2 - Igualdade na licitação. 3 - Requisitos para a participação em licitações: capacidade técnica, financeira e jurídica. IV - As diferenças entre as cooperativas e as demais sociedades. 1 - Conceito de cooperativas. 1.1. Ato cooperativo e ato não-cooperativo. 1.2. Reflexos tributários dos atos cooperativos e atos não-cooperativos. 2 - Desigualdades tributárias. $V-$ As cooperativas e as licitações. 1 - Reflexos das desigualdades e os requisitos da licitação. 2 - Reflexos das desigualdades $e$ os princípios da licitação. VI - Conclusões. VII - Bibliografia.

\section{I - Introdução}

Por mais de uma vez, colocaram-nos a questão de se as cooperativas poderiam participar de licitações de órgãos públicos. Algumas vezes, a colocação foi diversa, traduzindo-se em assertiva: as cooperativas não podem participar de licitações públicas. A justificativa, para esse entendimento, encontra-se no fato, para eles seguro, de que as cooperativas são detentoras de benefícios que as demais empresas não possuem, principalmente porque não pagam tributos.

Decidimos, então, aprofundarmo-nos um pouco mais no tema, para averiguar se as diferenças existentes entre tais sociedades e as demais são relevantes para a Administração Pública, notadamente no que se referem às licitações.

Entendemos que o caminho a ser trilhado vai através do conhecimento das igualdades e diferenças entre elas existentes entre as cooperativas e as outras formas organizacionais, e sua repercussão para a licitação.

* Juiz Federal da $3^{2}$ Região. Auxiliar de ensino, mestre e doutor em Direito Tributário na PUC/SP.

R. Dir. Adm.,

Rio de Janeiro, 224: 51-77, abr./jun. 2001 
Iniciamos o presente estudo pelo princípio da igualdade, para a Administração e para a licitação, de maneira perfunctória, porque esse já foi por nós tratado em monografia publicada no livro Princípios Informadores do Direito Administrativo, ${ }^{1}$ ao qual remetemos o leitor. Entretanto, nos pontos necessários ao deslinde da questão, voltamos àquele estudo, repensamos alguns aspectos e consultamos outros autores. Porém, as remissões que faremos ao texto e aos autores que o fundamentaram têm o intuito, exclusivo, de organizar logicamente nossas idéias para o real entendimento sobre a matéria versada.

Estruturado o entendimento pelo princípio da igualdade nas licitações da Administração Pública, apresentaremos alguns dados básicos sobre as cooperativas, dando ênfase para as apontadas diferenças que tais sociedades possuem frente as demais, que lhe particularizam, averiguando a extensão dessas particularidades no que diz respeito à tributação.

Por fim, enfrentamos o tema que resta assim colocado: podem as cooperativas participar das licitações públicas? O que respeita o princípio da igualdade na licitação: a possibilidade de participação ou de não participação dessas sociedades no certame?

Uma defesa prévia é necessária ao trabalho que aqui é tornado público. Quando se escreve sobre tema pouco ou nada versado, como nos parece ser o presente, fica o autor muito exposto a desentendimentos, críticas, discordâncias e contraditas. Sabemos que estamos totalmente sujeitos a tais acontecimentos e estamos muito tranquiilos para enfrentá-los no momento oportuno, desejando mesmo que seja possível abrir uma discussão sobre o tema que faça avançar os conhecimentos das licitações e das cooperativas.

\section{II - Breves colocações sobre o princípio da igualdade}

\section{1 - Igualdade formal e igualdade substancial}

A luta pela igualdade é um dos temas mais debatidos nos últimos séculos. Estando em permanente estado de evolução, tem importância tão grande que seu conceito se confunde mesmo com a idéia de justiça. ${ }^{2}$

Existem vários pontos relativos ao seu significado que poderiam ser abordados. Destacaremos, aqui, apenas dois, que ligam-se diretamente ao deslinde da problemática abordada. Primeiro, é importante fazermos uma distinção entre igualdade formal e igualdade substancial. Segundo, é mister que entendamos a distinção entre igualdade $n a$ lei e igualdade perante a lei.

1 "O princípio da igualdade no Direito Administrativo". Editora NDJ. 1997. Organização de Lúcia Valle Figueiredo.

2 Norberto Bobbio, Igualdade e Liberdade, $2^{\mathrm{a}}$. ed. 14. O autor aponta que para Aristóteles igualdade e justiça são conceitos que se confundem. 


\section{2 - Princípio da Igualdade}

A igualdade é um conceito, ou um valor social, extremamente abstrato, posto que as pessoas são, intrinsecamente, diferentes. Por isso, é tão importante conhecermos os contornos já identificados pela doutrina, que possibilitam a redução da abstratividade mencionada. Nesse caminho, vale determo-nos na diferença entre igualdade formal e igualdade substancial.

A igualdade substancial traduz-se como a busca da igualdade material, dos bens, dos confortos que a vida moderna pode propiciar. Quer extirpar as desigualdades sociais, fazendo com que todos os indivíduos tenham os mesmos bens materiais.

A igualdade substancial, conforme nos explica Celso Bastos

“...postula o tratamento uniforme de todos os homens. Não se trata, como se vê, de um tratamento igual perante o direito, mas de uma igualdade real e efetiva perante os bens da vida".

Em nossa atual Constituição Federal, podemos observar, como exemplos de igualdade substancial, os seguintes incisos do artigo $7^{\circ}$ :

"XXX - proibição de diferença de salários, de exercício de funções e de critérios de admissão por motivo de sexo, idade, cor ou estado civil;

$X X X I$ - proibição de qualquer discriminação no tocante a salário e critério de admissão do trabalhador portador de deficiência;

XXXII - proibição de distinção entre trabalho manual, técnico e intelectual ou entre os profissionais respectivos."

Essa igualdade foi buscada no ideário comunista, tendo surgido com a Revolução Industrial, quando os plebeus foram separados em classes de proprietários e de operários.

A preocupação maior do jurista, todavia, não está na isonomia substancial, mas na igualdade formal, segundo os ensinamentos de Celso Bastos, para quem esta:

“...consiste no direito de todo cidadão não ser desigualado pela lei senão em consonância com os critérios albergados ou ao menos não vedados pelo ordenamento constitucional". 4

É a igualdade perante os Direitos, ou igualdade de direitos. Para esse tipo de isonomia, não vamos mais utilizar como parâmetro aspectos materiais, mas sim aspectos formais. Nesses, inclui-se o Direito, que vive de formas. Pela igualdade formal, as pessoas devem ter as mesmas oportunidades, independentemente de suas particularidades pessoais. Se a igualdade substancial pugna por terem as pessoas as 
mesmas coisas, os mesmos bens materiais, a formal contenta-se com o mesmo tratamento jurídico. Para essa doutrina, todos devem ter o mesmo tratamento, o que levou a análises sarcásticas, como a célebre que diz que a lei proíbe igualmente a pobres e ricos roubar pão e dormir em parques públicos. ${ }^{5}$

Essa igualdade formal é difícil de ser alcançada, mas não impossível, pois envolve elementos subjetivos para sua adequada aplicação, ao lado de elementos previamente consignados pela Constituição, que veda discriminação baseada em sexo, raça, cor, religião e outros.

José Afonso da Silva explica o aspecto formal do princípio:

“Nossas constituições, desde o Império, inscreveram o princípio da igualdade, como igualdade perante a lei, enunciado que, na sua literalidade, se confunde com a mera isonomia formal, no sentido de que a lei e sua aplicação trata a todos igualmente, sem levar em conta as distinções de grupos. A compreensão do dispositivo vigente, nos termos do art. $5^{\circ}$, caput, não deve ser assim tão estreita. $O$ intérprete há que aferi-lo com outras normas constitucionais, conforme apontamos supra e, especialmente, com as exigências da justiça social, objetivo da ordem econômica e da ordem social." 6

Vemos que o autor supracitado já tempera o rigor da doutrina, preparando o entendimento mais compatível com a riqueza da vida fáctica, multifacetária por excelência.

Porém, quem trouxe mais luz ao nosso trabalho foi Meirelles Teixeira, ao apresentar uma terceira forma de tratamento para o princípio da isonomia, ao lado da igualdade formal e da igualdade substancial, que entendemos poder denominar de igualdade jurídica proporcional. ${ }^{7}$ Nota-se, entretanto, que o autor utiliza a terminologia orgânico-personalista, para contrapor à liberal-individualista. ${ }^{8}$

O Direito, explica Meirelles Teixeira, trata as desigualdades sociais de três formas possíveis:

a) tratando igualmente todos os indivíduos e todas as situações (posição liberal-individualista);

b) destruindo as desigualdades e buscando a igualdade de fato, socialmente absoluta, sem classes (posição igualitária);

c) distinguindo duas categorias: desigualdades legítimas (baseada nos dotes naturais de talento, inteligência, aptidões, virtudes, esforço, vontade retamente en-

5 “Neste caso está também o estudo das aplicações práticas do princípio da igualdade de todos perante a lei. ANATOLE FRANCE satirizou-o de modo candente, ao dizer que a lei, na majestade do seu igualitarismo, pró́be tanto aos ricos como aos pobres dormir nos parques e roubar pão"'. Víctor Nunes Leal. Problemas de Direito Público. págs. 31-2.

6 Curso de Direito Constitucional Positivo. $9^{a}$ ed., p. 198.

7 Utilizamos o termo em nosso Tributação das Cooperativas.

8 Curso de Direito Constitucional. p. 740. 
caminhada) e desigualdades ilegítimas (desigualdades artificiais, criadas apenas pelos azares, desajustamentos ou injustiças da ordem social) ${ }^{9}$.

$\mathrm{O}$ autor anteriormente citado completa a lição:

"Ora é evidente que não pode ser a mesma a posição do Estado em face dessas duas ordens ou espécies de desigualdades, pois as primeiras (desigualdades legítimas) devem ser reconhecidas, amparadas e mesmo estimuladas, ao passo que as segundas (desigualdades ilegítimas) devem ser combatidas, seja suprimindo-se as suas causas (reformas sociais e políticas, política geral do Estado), seja amparando-se os mais fracos, ou ainda atenuando-se ou mesmo suprimindo-se as situações ilegítimas de desigualdade (supressão de privilégios, de distinções injustas)". ${ }^{10}$

Então, não há como se falar em uma ordem pura, quer substancial, quer formal, no campo do direito à igualdade. É assim que nossa Constituição Federal elege como princípio fundamental do Estado brasileiro a livre iniciativa (art. $1^{\circ}$, IV) - volta a tratar dela como princípio geral da atividade econômica (art. 170) -, mas apresenta todo um suporte social, que denominamos de Seguridade Social, em que inclui, citando pelos demais, a "cobertura dos eventos de doença, invalidez, morte, incluídos os resultantes de acidentes do trabalho, velhice e reclusão" (inciso I do art. 201). ${ }^{11}$

Pela igualdade jurídica proporcional, em alguns momentos trabalha-se com a igualdade formal, em outros com a igualdade substancial, como fez nossa Constituição Federal. Pensando dessa forma, estamos dando um passo adiante, não mais apresentando três doutrinas para a igualdade, mas uma evolução do conceito, em que surge uma proposta conciliadora. É dizer, os opostos (igualdade formal e igualdade substancial) estão juntos no mesmo conceito, que para certos aspectos concretos determina a aplicação, a incidência, de um e para certos aspectos a incidência de outro. É exatamente o que disse Meirelles Teixeira: algumas desigualdades devem ser incentivadas pelo sistema, outras devem ser combatidas.

Bobbio, no prefácio de seu lgualdade e Liberdade, aponta que a existência absoluta desses valores (liberdade e igualdade) só ocorrerá numa sociedade hipotética, posto que na realidade histórica da vida dos homens, o amplamente desejado nem sempre é o possível. Afirma, ainda, que também haverá variações nos desejos acima expostos dependendo da posição do sujeito na escala social (os poderosos podem não desejar tanto a igualdade quanto os não-poderosos). Uma sociedade pode basear-se na hierarquia (como a sociedade militar), não havendo, por conseguinte, igualdade. Além disso, existem as próprias limitações a tais preceitos. Nas palavras do grande pensador italiano:

“Apesar de sua desejabilidade geral, liberdade e igualdade não são valores absolutos. Não há princípio abstrato que não admita exceções em sua

9 Idem, ibidem, p. 728-9.

10 Idem, ibidem, p. 729. As informações entre parênteses são nossas.

11 A Constituição Federal trata do Seguro Social nos arts. 194 a 204. 
aplicação. A diferença entre regra e exceção está no fato de que a exceção deve ser justificada. Onde a liberdade é a regra, sua limitação deve ser justificada. Onde a regra é a igualdade, deve ser justificado o tratamento desigual. Mas o ponto de partida pode também ser oposto, como na escola ou num quartel, onde a regra é a disciplina e a liberdade é exceção. Decidir o que é mais normal, se a liberdade ou a disciplina, a igualdade ou a hierarquia, não é algo que se possa fazer de uma vez por todas. Liberdade $e$ igualdade são mais normas do que disciplina e hierarquia somente em sentido normativo, no universo do dever ser. Não me resulta que, entre as várias elucubraçōes sobre sociedades ideais, exista uma só na qual os cidadãos não sejam nem livres nem iguais, embora uma sociedade de livres e iguais não conheça nem tempo nem lugar". ${ }^{12}$

Assim, o ponto principal está na justificação. Nesse momento em que igualdades e desigualdades convivem no mesmo sistema, toda aplicação deve ser justificada. Por isso, Bobbio afirmou que não se pode determinar de uma vez por todas, a aplicação de um desses conceitos, como a igualdade.

Também para J. J. Gomes Canotilho as teorias da igualdade material (substancial) e formal não são suficientes. Vejamos suas considerações:

"Reduzido a um sentido formal, o princípio da igualdade acabaria por se traduzir num simples princípio de prevalência da lei em face da jurisdição e da administração. Conseqüentemente, é preciso delinear os contornos do princípio da igualdade em sentido material. Isto não significa que o princípio da igualdade formal não seja relevante nem seja correcto. Realça-se apenas o seu carácter tendencialmente tautológico, 'uma vez que o cerne do problema permanece irresolvido, qual seja, saber quem são os iguais e quem são os desiguais". ${ }^{13}$

A solução para esta problemática vem a seguir:

"A fórmula 'o igual deve ser tratado igualmente e o desigual desigualmente' não contém o critério material de um juízo de valor sobre a relação de igualdade (ou desigualdade). A questão pode colocar-se nestes termos: o que é que nos leva a afirmar que uma lei trata dois indivíduos de uma forma igualmente justa? Qual o critério de valoração para a relação de igualdade? Uma possivel resposta, sufragada em algumas sentenças do Tribunal Constitucional, reconduz-se à 'proibição geral do arbítrio': existe observância da igualdade quando indivíduos ou situações iguais não são arbitrariamente (proibição do arbítrio) tratados como desiguais. Por outras palavras: o

12 Op. cit., p. 10

13 Direito Constitucional e Teoria da Constituição. págs. 389-90. 
princípio da igualdade é violado quando a desigualdade de tratamento surge como arbitrária. $O$ arbítrio da desigualdade seria condição necessária e suficiente da violação do principio da igualdade. Embora ainda hoje seja corrente a associação do princípio da igualdade com o princípio da proibição do arbítrio, este princípio, como simples princípio de limite, será também insuficiente se não transportar já, no seu enunciado normativo-material, critérios possibilitadores da valoração das relações de igualdade e desigualdade. Esta a justificação de o princípio da proibição do arbítrio andar sempre ligado a um critério material objectivo. Ele costuma ser sintetizado da forma seguinte: existe uma violação arbitrária da igualdade jurídica quando a disciplina jurídica não se basear num: (i) fundamento sério; (ii) não tiver um sentido legítimo; (iii) estabelecer diferenciação jurídica sem um fundamento razoável". ${ }^{14}$

Nesse passo, sua doutrina aproxima-se muito da de Celso Antônio Bandeira de Mello, exposta em $O$ Conteúdo Jurídico do Princípio da Igualdade, onde vemos que somente como resultado da análise da relação entre três elementos é possível determinar-se quando haja inconstitucionalidade frente ao princípio posto na berlinda:

“a) a primeira diz com o elemento tomado como fator de desigualação;

b) a segunda reporta-se à correlação lógica abstrata existente entre ofator erigido em critério de discrímine e a disparidade estabelecida no tratamento jurídico diversificado;

c) a terceira atina à consonância desta correlação lógica com os interesses absorvidos no sistema constitucional e destarte juridicizados". ${ }^{15}$

Até mesmo a ausência de diferenciação pode ser fator discriminatório. Um tratamento igual muitas vezes pode imbutir uma lesão ao princípio. Tal ocorrerá se a desigualdade for necessária para equiparar os sujeitos.

Por tudo isso, o leitor atento começa a perceber que a igualdade aplicada às licitações públicas não aceita mais respostas simplistas ou superficiais. Terão que ser justificadas as igualdades e as desigualdades, quer formais, quer substanciais. Se as cooperativas forem desiguais para fins de participação em certames preparatórios de contratos administrativos, que se justifique. Ao contrário, se forem iguais, o procedimento será o mesmo, justificado.

Mas, antes de ingressarmos propriamente no campo das licitações públicas, vamos continuar um pouco mais no campo da teoria geral, para tratarmos da igualdade perante a lei.

14 Idem, ibidem, págs. 390-1.

$15 \mathrm{O}$ conteúdo jurídico do princípio da igualdade. p. 21. 


\section{3 - Igualdade na lei e igualdade perante a lei}

A doutrina ressalta, também, a existência de distinção entre a igualdade perante a lei e a igualdade na lei. ${ }^{16}$ No texto constitucional está dito que todos são iguais perante a lei e vários autores se referem a essa igualdade. ${ }^{17}$

Para Kelsen, a isonomia perante a lei não possuía significação para a igualdade constitucional, estando ligada ao princípio da regularidade da aplicação do direito em geral. O sentido está na igualdade na lei, conforme citação e explicação da posição do mestre de Viena feita por Celso Antônio Bandeira de Mello. ${ }^{18}$

Lúcia Figueiredo também expõe as diferenças entre a igualdade na lei e perante a lei:

“Como já afirmei, igualdade na lei e igualdade perante a lei são coisas diferentes. $O$ aplicador poderá, ao aplicar a lei, estar aplicando-a igualmente, estar aplicando a lei sem discriminações, mas poderá, ao aplicar a lei, estar violando o texto constitucional, na medida em que a lei tem de ser aferida pelas normas e princípios da Constituição". ${ }^{19}$

Mas, afinal, que é igualdade na lei e igualdade perante a lei? Para a doutrina que sustenta a existência dessa dicotomia, igualdade perante a lei significa simplesmente igualdade na aplicação da lei. É o princípio sendo válido para os momentos posteriores ao surgimento da norma. Assim, todos são iguais perante a lei: todas as mulheres são iguais, entre si, perante a lei; todos os homens também são iguais, entre si, perante a lei; mas a lei não diz que homens e mulheres são iguais entre si. A igualdade, aqui, é perseguida após a criação da lei, para o momento de suas aplicações.

Já a igualdade na lei significa a aplicação do princípio desde a elaboração da norma. Todos são iguais na lei, dentro da lei, para o criador da lei. É dizer: homens e mulheres são iguais na lei. São iguais para a lei, mesmo que possuam diferenças entre si.

José Afonso da Silva vai destacar que:

"Mas, como já vimos, o princípio não pode ser entendido em sentido individualista, que não leve em conta as diferenças entre grupos. Quando se diz que o legislador não pode distinguir, isso não significa que a lei deva tratar todos abstratamente iguais, pois o tratamento igual - esclarece Petzold - não se dirige a pessoas integralmente iguais entre si, mas àquelas

16 Segundo José Afonso da Silva, apenas a doutrina estrangeira os diferencia. Dentre nós, seria a mesma coisa uma e outra, havendo apenas uma questão de terminologia.

17 "Neste caso está também o estudo das aplicações práticas do princípio da igualdade de todos perante a lei." Víctor Nunes Leal, p. 31. O negrito é nosso.

18 Conteúdo Jurídico do Princípio da lgualdade, cit., p.10.

19 Curso de Direito Administrativo. p. 46. 
que são iguais sob os aspectos tomados em consideração pela norma, o que implica que os 'iguais' podem diferir totalmente sob outros aspectos ignorados ou considerados como irrelevantes pelo legislador. Este julga, assim, como 'essenciais' ou 'relevantes', certos aspectos ou características das pessoas, das circunstâncias ou das situações nas quais essas pessoas se encontram, e funda sobre esses aspectos ou elementos, as categorias estabelecidas pelas normas jurídicas; por conseqüência, as pessoas que apresentam os aspectos 'essenciais' previstos por essas normas, são consideradas encontrar-se nas 'situações idênticas', ainda que possam diferir por outros aspectos ignorados ou julgados irrelevantes pelo legislador; vale dizer que as pessoas ou situações são iguais ou desiguais de modo relativo, ou seja, sob certos aspectos. Nesse sentido, já se pronunciou, também, Seabra Fagundes, para lembrar que os 'conceitos de igualdade e de desigualdade são relativos, impõem a confrontação e o contraste entre duas ou várias situações, pelo que onde uma só existe não é possivel indagar de tratamento igual ou discriminatório". ${ }^{20}$

Daí, vamos ver que as cooperativas são diferentes das demais sociedades. Existem particularidades que lhes são próprias. Mas tais particularidades são relevantes para fins de licitação? É isso que esse trabalho pretende demonstrar. Vamos manter na retentiva a lição de José Afonso da Silva quanto aos "aspectos essenciais", já que igualdade e desigualdade são conceitos relativos, dependendo do sentido para o qual a norma foi criada.

\section{4 - Igualdade na Administração Pública}

A Administração Pública é regida por princípios gerais de Direito e princípios específicos de Direito Administrativo, que orientam a conduta dos administradores no trato da coisa pública. Tais princípios vêm explícitos ou implícitos na Constituição e nas leis do País.

A identificação e organização dos princípios, que auxiliam valiosamente a sistematização do Direito, é, muitas vezes, uma decisão pessoal do estudioso. Isso porque podem ser aglutinados ou divididos de acordo com a interpretação dada por cada autor, pelo destaque que um ponto possa despertar-lhe ou, ao contrário, pela desimportância dada a outro aspecto.

Assim, vemos que Hely Lopes Meirelles apontava como princípios básicos da administração pública a legalidade, a moralidade, a impessoalidade e a publicidade. ${ }^{21}$ Lúcia Valle Figueiredo estuda os princípios da Administração Pública e os constitucionais: legalidade, igualdade, razoabilidade, motivação, boa-fé, moralidade administrativa, publicidade e impessoalidade ${ }^{22}$ mas trata ao longo de sua obra de vários

20 Curso de Direito Constitucional Positivo, cit., págs. 197-8.

21 Direito Administrativo Brasileiro, p. 82 e segs.

22 Curso de Direito Administrativo, p. 35 e segs. 
outros infraconstitucionais. Celso Antônio Bandeira de Mello acrescenta aos constitucionais apontados por Lúcia Valle Figueiredo a supremacia do interesse público sobre o interesse particular, o princípio da finalidade, o princípio da proporcionalidade, o princípio do controle judicial dos atos administrativos e o princípio da responsabilidade do Estado por atos administrativos. ${ }^{23}$

A Constituição Federal aponta no artigo 37:

"Art. 37. A administração pública direta, indireta ou fundacional, de qualquer dos Poderes da União, dos Estados, do Distrito Federal e dos Municípios obedecerá aos princípios de legalidade, impessoalidade, moralidade, publicidade e eficiência e, também, ao seguinte" ${ }^{24}$

Vemos como princípio comum, independentemente do autor ${ }^{25}$ ou do legislador, a igualdade ou isonomia.

Esse valioso e importante princípio é primordialmente dirigido à Administração Pública, como se nota na doutrina de Canotilho:

"A igualdade na aplicação do direito continua a ser uma das dimensões básicas do princípio da igualdade constitucionalmente garantido e, como se irá verificar, ela assume particular relevância no âmbito da aplicação igual da lei (do direito) pelos órgãos da administração e pelos tribunais". 26

A Administração Pública, por sua vasta atuação e pelo seu poder de construir e destruir vidas e bens, precisa estar mais atenta do que qualquer outra instituição, para fazer valer o ideal superior da igualdade, muitas vezes confundida mesmo com a Justiça.

\section{III - Igualdade na licitação}

\section{1 - Princípios regedores da licitação}

A identificação de princípios jurídicos é, no mais das vezes, uma decisão pessoal de cada autor, como dito anteriormente.

No que tange à licitação, Lúcia Valle Figueiredo diz que a doutrina, em sua maioria, encampou os princípios da igualdade, da concorrência e da moralidade. ${ }^{27}$

23 Curso de Direito Administrativo, p. 52 e segs.

24 Com a redação dada pela Emenda Constitucional $n^{\circ} 19$.

25 Para Hely Lopes Meirelles, a igualdade inclui-se dentro da legalidade.

26 Direito Constitucional ..., cit., p. 389

27 Direito dos Licitantes. p. 22. 
A legislação federal aponta os princípios que regem as licitações no artigo $3^{\circ}$ da Lei 8.666/93.

Celso Antônio Bandeira de Mello elege o princípio da igualdade como o mais importante:

“Quanto a nós, rejeitamos, de logo, à força aberta, o último dos princípios enunciados - posto que não nos parece a adjudicação seja sempre obrigatória - (...) consideramos suficientes os seguintes: a) isonomia; b) publicidade; c) respeito às condições prefixadas no edital; d) possibilidade do disputante fiscalizar o atendimento dos princípios anteriores. Sem embargo, julgamos que todos descendem do primeiro, pois são requisitos necessários à sua existência ou à fiscalização de sua real ocorrência. ...

Afinal, o acatamento aos princípios mencionados empece - ou aos menos forceja por empecer - conluios inadmissiveis entre agentes governamentais e terceiros, no que se defende a atividade administrativa contra negócios desfavoráveis, levantando-se, ainda, óbice a favoritismos ou perseguições, inconviventes com o princípio da igualdade" ${ }^{28}$

A igualdade citada pela lei e pela doutrina para a licitação é a mesma igualdade constitucional e doutrinária. Não é outra igualdade, ou não é uma igualdade diferenciada, com contornos específicos. Absolutamente não. Por isso, todos os dados anteriormente mencionados como enquadradores, ou delimitadores, do princípio geral, são transpostos para as licitações.

José Afonso da Silva elenca, dentre os princípios constitucionais da Administração Pública, o princípio da licitação pública, instrumento de realização dos princípios da moralidade administrativa $e$ do tratamento isonômico dos eventuais contratantes. ${ }^{29} \mathrm{O}$ autor ressalta o tratamento isonômico, demonstrando que a igualdade é de tratamento, não uma igualdade entre os licitantes.

Assim, nos resta aplicar as preocupações com a igualdade jurídica proporcional e as lições de Celso Antônio Bandeira de Mello e J. J. Gomes Canotilho.

\section{2 - Igualdade na licitação}

Qual a extensão da igualdade no que concerne às licitações públicas? Antes de responder a essa pergunta, gostaríamos de afirmar que defendemos a aplicação do princípio da igualdade nas licitações muito antes de surgir a atual polêmica sobre se as cooperativas podem ou não participar de licitações. Pelo contrário, nós mesmos já afirmamos sobre o princípio da igualdade nas licitações: 
“A igualdade é princípio aplicável posto que a Administração Pública busca, através do procedimento licitatório, identificar a melhor proposta, que inclui o melhor preço, no melhor prazo e com a melhor qualidade. $O$ interesse público assim o exige.

No que toca à igualdade, sua relevância está em que a Administração Pública somente poderá identificar a melhor proposta se todos os interessados tiverem acesso à licitação. A competição propiciará a identificação da situação melhor para o cumprimento do fim público, acima dos interesses particulares dos contratantes e dos administradores.

E como a igualdade será respeitada? Através da segurança de que todos os interessados tenham acesso ao procedimento, ao conhecimento de seus termos e tenham condiçōes razoáveis de participar do certame. Assim, não basta a publicação de seus termos. Esta é útil e necessária, mas a exigência do princípio da igualdade lhe supera. Se os prazos para retirada do edital completo ou da apresentação de documentação forem muito exíguos (e isto só pode ser reconhecido em cada caso concreto), pode estar a demonstrar que nem todos os interessados terão acesso ao certame. É por isso que a lei de licitações determina certos prazos, mínimos, para garantir a publicidade". ${ }^{30}$

Toda a dificuldade acentuada sobre a igualdade, ou justiça, será aplicada na licitação. Não vimos nenhum autor dizer que a igualdade na licitação é outra que a estudada pelo Direito Constitucional ou pela Teoria Geral do Direito.

Observe-se, com essa visão, ao ensinado por Maria Sylvia Zanella Di Pietro:

“ $O$ 'princípio da igualdade' constitui um dos alicerces da licitação, na medida em que esta visa, não apenas permitir à Administração a escolha da melhor proposta, como também assegurar igualdade de direitos a todos os interessados em contratar". ${ }^{31}$

Pela citação exemplificativa, extraímos que não há nenhuma diferenciação entre o princípio geral e o específico. Se houvesse, teria que ser alardeado pela doutrina e constaria do Direito Positivo. Conforme vem disposto na Constituição Federal, quando esta trata da exigência de licitação (art. 37, inc. XXI), a igualdade exigida refere-se às condições, às oportunidades de participação no certame. Diz a Constituição:

“Art. 37. A administração pública direta, indireta ou fundacional, de qualquer dos Poderes da União, dos Estados, do Distrito Federal e dos Muni-

30 "O Princípio da Igualdade no Direito Administrativo", in Princípios Informadores do Direito Administrativo, cit. pág. 67.

31 Direito Administrativo, cit., p. 258. 
cípios obedecerá aos princípios de legalidade, impessoalidade, moralidade, publicidade e eficiência e, também, ao seguinte:

$\ldots$

$X X I$ - ressalvados os casos especificados na legislação, as obras, serviços, compras e alienações serão contratados mediante processo de licitação pública que assegure 'igualdade de condições' a todos os concorrentes, com cláusulas que estabeleçam obrigações de pagamento, mantidas as condições efetivas da proposta, nos termos da lei, o qual somente permitirá as exigências de qualificação técnica e econômica indispensáveis à garantia do cumprimento das obrigações" (destaques nossos).

Não há previsão expressa no texto de que os licitantes devam ser iguais entre si. Entendemos que nem poderia haver previsão expressa nesse sentido, por impossibilidade lógica, já que não há dois seres completamente iguais entre si. Desigualdades são inerentes às pessoas físicas e jurídicas. Teremos que buscar as igualdades e desigualdades relacionadas com a licitação. Quais seriam as igualdades necessárias e quais as desigualdades permitidas para fins licitatórios?

A igualdade só pode ser de tratamento. Hely Lopes Meirelles, com toda a clareza de raciocínio que lhe era peculiar, expressou melhor a aplicação do princípio em comento nas licitações. Ouçamo-lo:

" a igualdade entre os licitantes é princípio impeditivo da discriminação entre os participantes do certame, quer através de cláusulas que, no edital ou convite, favoreçam uns em detrimento de outros, quer mediante julgamento faccioso, que desiguale os iguais ou iguale os desiguais (art. $3^{\circ}, \S$ $1^{\circ}$ ).

O desatendimento a esse princípio constitui a forma mais insidiosa de desvio de poder, com que a Administração quebra a isonomia entre os licitantes, razão pela qual o Judiciário tem anulado editais e julgamentos em que se descobre a perseguição ou o favoritismo administrativo, sem nenhum objetivo ou vantagem de interesse público. Todavia, não configura atentado ao princípio da igualdade entre os licitantes o estabelecimento de requisitos mínimos de participação no edital ou convite, porque a Administração pode e deve fixá-los sempre que necessário à garantia da execução do contrato, à segurança e perfeição da obra ou serviço, à regularidade do fornecimento ou ao atendimento de qualquer outro interesse público" ${ }^{32}$

Se é a igualdade geral, a mesma para todo o direito, vamos transportar os conhecimentos declarados nos itens precedentes para a licitação pública. Assim sendo, vamos voltar à igualdade formal, substancial e jurídica proporcional, à igualdade perante a lei e na lei e aos discrímines apoiados em correlação lógica com o fundamento da norma discriminadora. 
Sendo a igualdade substancial a luta pelos mesmos bens materiais, correto dizer tratar-se de uma isonomia de resultado. Como a licitação é um procedimento de escolha de contratante, não há correlação lógica com a isonomia substancial, nem mesmo em alguns aspectos, pelo que afastamos também a igualdade jurídica proporcional.

Infere-se, portanto, tratar-se de uma isonomia formal, resultando da disposição licitatória a obrigação pela igualdade de tratamento. Com isso, queremos destacar, de uma vez por todas, que a Administração deve propiciar o mesmo tratamento a todos os participantes do procedimento.

Como a igualdade perante a lei é um mero reflexo do princípio da legalidade (Kelsen), a isonomia na lei de licitações demonstra que a Administração deve tratar todos de forma equivalente. Em princípio, todos os futuros licitantes já são iguais para a lei e devem ser tratados da mesma forma.

Vamos analisar, agora, quais os discrímines (Celso Antônio) genericamente possíveis para discriminar-se na licitação pública sem com isso afastar-se da esfera da legalidade. Referimo-nos às genericamente possíveis, porque é ínsito ao conceito sua complementação possível exclusivamente analisando-se o caso fático.

Entendemos que os parâmetros são três: os capazes jurídica, econômica e tecnicamente, que serão analisados a seguir.

3 - Requisitos para a participação em licitações: capacidade técnica, financeira e jurídica

Quanto aos requisitos para a participação em licitações, a legislação de regência os especifica em capacidade técnica, financeira e jurídica.

A capacidade técnica corresponde à possibilidade do licitante executar o contrato. Deve demonstrar os conhecimentos exigidos para cumprir com a obrigação a que se apresenta.

A capacidade financeira relaciona-se com a comprovação de ter, o licitante, meios econômicos necessários para suportar os encargos do contrato até o momento da contraprestação da Administração Pública.

A capacidade jurídica exterioriza-se na detenção, por parte do licitante, dos requisitos de direito para celebração de contratos.

Esses três requisitos são importantes porque não cabe à Administração lançar-se em aventuras, devendo cercar-se de cautelas frente aos seus contratantes, reservando-se de futuros dissabores indesejados. É assim que Celso Antônio Bandeira de Mello os apresenta:

"Com efeito, interessa, como é lógico, cifrar a disputa a quem tenha realmente condições de vir a cumprir o pretendido pelo Poder Público. À Administração não convém atirar-se em negócios aleatórios. Não pode envolver-se em riscos que tragam incerteza quanto ao efetivo cumprimento dos encargos que poderão incidir sobre a parte vencedora. 
$O$ interesse público, a continuidade do serviço, não se compadecem com álea que derivaria de avença travada com quem pudesse comprometer, por insuficiência econômica ou técnica, a satisfação dos superiores interesses curados pelo Poder Público. Menos ainda poderia vincular-se a quem não tivesse aptidão jurídica para tanto. Destarte, uma empresa de recursos financeiros ou técnicos modestos não poderá envolver-se em operações de vulto, que excedam, pelos compromissos a eles inerentes, a normal e demonstrada capacidade de enfrentar situações análogas e de equivalente porte. É obvio que ao Poder Público não assenta, mediante o instituto da licitação, propiciar a expansão econômica de organizações de porte menor".33

Esses requisitos são de natureza objetiva, sem possibilidade de abertura para discriminações sem correlação lógica para os interesses da Administração, que vai cifrar-se unicamente a verificar se os que acorreram ao certame preenchem ou não os requisitos necessários para disputá-la, segundo os termos prefixados no edital, ${ }^{34}$ na lição sempre escorreita de Celso Antônio Bandeira de Mello.

Assim, os juridicamente aptos a participar de uma licitação são aqueles que estão regularmente registrados, com sua documentação legal em ordem. A possibilidade de discriminação nesse campo reside em afastar os licitantes que possuem problemas legais, o que poderia comprometer a normal execução do contrato ou, em caso de descumprimento, frustar os mecanismos aplicáveis a tais hipóteses.

A base do raciocínio é a mesma para os outros dois requisitos: só se pode discriminar entre os aptos e os não aptos. Por isso, todos aqueles que comprovarem suficiência econômica para suportar os encargos do contrato estarão em igualdade, ao contrário daqueles que não podem suportar tais encargos. Esses serão discriminados. E no campo da técnica, o grupo se dividirá também entre os que possuem (e comprovem) os conhecimentos para a execução do ajustado e os que não possuem. Esses também serão os discriminados.

Maria Sylvia Zanella Di Pietro aponta, no mesmo sentido que nós, a particularidade de que tais requisitos desigualam os licitantes:

"Embora tenha que haver competição, ela não é inteiramente livre, pois a proteção do interesse público exige a imposição de certas normas que afastam, por exemplo, as pessoas jurídicas não regularmente constituídas, as que não apresentam idoneidade técnica ou financeira". ${ }^{35}$

Diante desse quadro, consideramos que fica muito difícil afastar as cooperativas das licitações pelo só motivo de serem sociedades criadas com essa forma jurídica. Mas, considerando que tais sociedades são desconhecidas juridicamente da maioria

33 Licitação, cit., págs. 37-8.

34 Idem, pág. 26.

35 Direito Administrativo, cit., p. 259. 
de nós, vamos apontar algumas particularidades existentes nessas sociedades, para identificarmos até onde vão as diferenças dessas entidades com as demais.

\section{IV - As diferenças entre as cooperativas e as demais sociedades \\ 1 - Conceito de cooperativas}

As cooperativas são associações de pessoas que se unem para atingir determinado fim específico, organizando um empreendimento com características diversas das demais pessoas jurídicas, tanto civis quanto comerciais.

Definimos a cooperativa como sendo a sociedade de pessoas, de cunho econômico, sem fins lucrativos, criada para prestar serviços aos sócios, de acordo com princípios jurídicos próprios e mantendo seus traços distintivos intactos.

Sociedade de pessoas porque, na linha exposta por Pontes de Miranda, ${ }^{36}$ o capital cede em importância para os membros individualizados, que não buscam na sociedade uma melhor remuneração para seus dinheiros, mas sim para seu trabalho.

O cunho econômico destaca que as cooperativas não são sociedades beneficentes ou culturais (mesmo se enfocarem tais atividades por liberalidade de seus membros). Os sócios visam incrementos econômicos para si, o que tem causado muita confusão para os desconhecedores da matéria, já que confundem conteúdo econômico com lucro. Não é o caso.

Entidade sem fim lucrativo posto que, como destacado, a cooperativa não existe para criar riqueza e depois distribui-la entre seus associados na proporção de sua participação societária. Este item está muito ligado com o anterior, tanto é que Pontes de Miranda explicou:

"O fim econômico, nas sociedades cooperativas, é atingido diretamente pelos sócios, em seus contactos com a sociedade. O fim econômico, nas sociedades lucrativas, é obtido com a repartição do que a sociedade percebeu de lucro. A diferença é sutil, porém sempre da máxima relevância".$^{37}$

Quanto à prestação de serviços, é esta a realidade da atividade cooperativista, independentemente do objeto da atuação da sociedade. Mesmo uma cooperativa de produção, com caráter industrial, adequa-se à afirmação. Isso porque as cooperativas são prestadoras de serviços para seus associados. Explica-se: a cooperativa sempre será um meio para uma melhoria da situação pessoal do associado, que beneficiarse-á imediatamente em suas atividades que motivaram sua participação na entidade. O cooperado visa, com a sociedade, diminuir seus custos ou obter melhores preços

36 Para Pontes de Miranda, "A sociedade cooperativa é sociedade em que a pessoa do sócio passa à frente do elemento econômico e as consequiências da pessoalidade são profundas, a ponto de torná-la espécie de sociedade". In Tratado de Direito Privado. Parte especial tomo XLIX. P. 429. 37 Tratado..., cit., p. 434. 
para seus produtos ou receber empréstimos a juros melhores, etc. ${ }^{38}$ A lei de regência dessas sociedades reconhece esta particularidade (Lei $\mathrm{n}^{\circ} 5.764 / 71$, art. $4^{\circ}$ ).

Os princípios jurídicos próprios que regem as cooperativas são a adesão livre, administração democrática, juro limitado ao capital, um certo destino aos excedentes, a promoção da educação e a prática da intercooperação. ${ }^{39} \mathrm{De}$ antemão, o leitor deve reter na memória que os princípios diferenciarão essas sociedades de outras sociedades, notadamente as comerciais. Disso decorre que as cooperativas que porventura não lhes sigam deixam de ser legais, devendo transformar-se em outra forma associativa.

Mantendo traços distintivos intactos, porque a sociedade que se mascara como cooperativa trai as normas de regência. Não preservando as distinções que possui com as demais sociedades jurídicas, não pode ser partícipe desse sistema próprio e deixa de ser cooperativa. Passa a ser uma falsa cooperativa, praticando o injusto, o injurídico e o ilegal. Utiliza-se de prerrogativas que não possui, abusa do corpo social que lhe apoia, beneficia-se indevidamente de qualidades que não possui, trazendo para si vantagens imerecidas. Cresce como erva daninha, empobrece o jardim e deve ser combatida como praga.

Com este conceito, fica claro que nós não procuramos esconder as particularidades das sociedades cooperativas. Pelo contrário, entendemos que essas devem ser acentuadas a cada instante, posto que foram criadas, historicamente, para ser uma reunião diferente de pessoas, com marcante cunho social.

A legislação de regência de tais sociedades não deixa margem para dúvidas quanto ao que estamos afirmando. Da Lei $n^{\circ}$. 5.764/71 extraímos que:

“Art. 4". As cooperativas são sociedades de pessoas, com forma e natureza juridica próprias, de natureza civil, não sujeitas a falência, constituídas para prestar serviços aos associados, distinguindo-se das demais sociedades pelas seguintes características:

I - adesão voluntária, com número ilimitado de associados, salvo impossibilidade técnica de prestação de serviços;

II - variabilidade do capital social, representado por quotas-partes;

III - limitação do número de quotas-partes do capital para cada associado, facultado, porém, o estabelecimento de critérios de proporcionalidade, se assim for mais adequado para o cumprimento dos objetivos sociais;

IV - incessibilidade das quotas-partes do capital a terceiros, estranhos à sociedade;

$V$ - singularidade de voto, podendo as cooperativas centrais, federaçōes e confederações de cooperativas, com exceção das que exerçam atividade de crédito, optar pelo critério da proporcionalidade;

VI - 'quorum' para o funcionamento e deliberação da Assembléia Geral baseado no número de associados e não no capital;

38 Pontes de Miranda, op. cit., p. 432.

39 Esses assuntos foram por nós tratados no livro Tributação das Cooperativas, cit. 
VII - retorno das sobras líquidas do exercício, proporcionalmente às operações realizadas pelo associado, salvo deliberação em contrário da Assembléia Geral;

VIII - indivisibilidade dos fundos de Reserva e de Assistência Técnica, Educacional e Social;

IX - neutralidade política e indiscriminação religiosa, racial e social;

$X$ - prestação de assistência aos associados, e, quando prevista nos estatutos, aos empregados da cooperativa;

$X I$ - área de admissão de associados limitada às possibilidades de reunião, controle, operações e prestação de serviços".

Por todo esse elenco de diferenciações, fica claro que existem muitas diferenças das cooperativas para as demais sociedades.

Apontamos que as diferenças são, em sua maioria, formais e não materiais. Ou, sob outro giro verbal, são diferenças intrínsecas, e não extrínsecas. Com isso queremos dizer que, observando-se uma cooperativa por seu funcionamento, não é possível, na maioria das vezes (exceção à participação societária, quando o associado vale por um voto, independentemente do número de quotas-partes que possuir) identificar suas distinções. Será preciso ver com olhos jurídicos, já que as distinções estarão nas formas. Isso não deve causar espécie ao operário do Direito, posto que tanto a Ciência quanto o Direito Positivo trabalham com formas, mas precisam ser bem entendidas, para o exato conhecimento de sua existência.

Não vamos aqui demonstrar as diferenças tópicas com cada uma dessas organizações civis ou comerciais, porque refogeria aos objetivos do presente trabalho. Vamos, apenas, ilustrar um ponto de diferenciação, dentre os onze acima elencados: a adesão voluntária.

O inciso I do artigo supracitado permite a adesão voluntária de qualquer interessado em participar da cooperativa. Este inciso contém um princípio universal do cooperativismo, adotado pela Aliança Cooperativista Internacional, entidade que agrega o movimento mundial. Tal princípio já foi nosso objeto de meditação no livro Tributação das Cooperativas, onde afirmamos:

"Porém, todos aqueles que virem uma cooperativa sendo bem sucedida e tenham os mesmos objetivos, têm direito a dela fazer parte. Um taxista, aproveitando o exemplo acima, que veja seus companheiros de profissão sendo beneficiados por uma cooperativa, poderá nela ingressar e usufruir os mesmos benefícios. Esse é um traço marcante, porque, nas demais sociedades, isso não acontece. Havendo uma transportadora, sociedade mercantil, da qual um caminhoneiro deseje participar como trabalhador $e$ proprietário, não terá ele direito de fazer parte dela. Isso porque não há uma exigência legal, nas demais sociedades, de acolher todos os interessados a sócio ou trabalhador, notadamente os dois juntos"..$^{40}$ 
Saindo da temática societária e ingressando na relativa ao exercício das atividades fins da cooperativa, julgamos importante tecer breves comentários sobre os atos cooperativos e os atos não-cooperativos, de aplicação direta para o deslinde da questão proposta.

\subsection{Ato cooperativo e ato não-cooperativo}

O que particulariza a cooperativa é o fato de o associado atuar como proprietário e como beneficiário (consumidor, contratante etc.) e uma relação ocorrer como resultado de outra, principalmente a segunda ser decorrência da primeira. É dizer: o consumidor típico de uma cooperativa é o seu sócio. Essas sociedades existem para que seus sócios consumam seus serviços, não para que eles se enriqueçam.

Disso decorre o chamado ato cooperativo, definido na Lei ${ }^{\circ} 5.764 / 71$, em seu artigo 79 , nos seguintes termos:

"Denominam-se atos cooperativos os praticados entre as cooperativas $e$ seus associados, entre estes e aquelas e pelas cooperativas entre si quando associadas, para a consecução dos objetivos sociais.

Parágrafo único. O ato cooperativo não implica operação de mercado, nem contrato de compra e venda de produto ou mercadoria."

Vamos dar alguns exemplos simples para melhor situarmos o leitor leigo (concessa venia o conhecedor do assunto). Um grupo de companheiros, em número de vinte, reúnem-se e formam uma cooperativa. Praticam democraticamente todos os atos necessários para a criação, como participação em Assembléia Geral de fundação, aprovação do Estatuto Social, eleição dos Conselhos de Administração e Fiscal. Aportam capital social. A cooperativa está apta a iniciar suas atividades

Seu objetivo pode ser facilitar o consumo dos cooperados e, assim, fundam um supermercado cooperativo. Será ato cooperativo a aquisição dos produtos expostos nas prateleiras, como se fosse qualquer supermercado, desde que a aquisição se dê por um cooperado.

Se o objetivo for facilitar o trabalho dos cooperados, através de melhor remuneração e condições laborais, criam uma cooperativa de trabalho e esta negociará com os interessados aquelas prestações de serviços de seus membros. As relações cooperativa-cooperativado serão atos cooperativos.

Se for uma cooperativa de crédito, será ato cooperativo o depósito de dinheiro e sua retirada, bem como os empréstimos e seu pagamento, desde que realizados por cooperados.

Numa cooperativa habitacional, a aquisição da moradia e seu pagamento será ato cooperativo, desde que com associado.

E assim sucede nos demais tipos de cooperativa, tendo todas elas sua forma de ato cooperativo.

Os atos não-cooperativos são identificados por exclusão: são aqueles que não se encaixam nos elementos que compõem a norma do art. 79 , citado. Sua autorização consta do art. 86 da lei de regência: 
“As cooperativas poderão fornecer bens e serviços a não associados, desde que tal faculdade atenda aos objetivos sociais e estejam de conformidade com a presente lei."

Se o supermercado cooperativo vende para não associado, será ato não-cooperativo. Nessa hipótese, a venda em nada diferirá, apesar das diferenças societárias apontadas, da venda de um supermercado que seja sociedade comercial.

Entendemos que algumas cooperativas podem realizar negócios com não associados, porque, como vimos pelo artigo 86, o Brasil não adotou o princípio do exclusivismo. Mas outras não (exemplo são as cooperativas habitacionais, que não podem vender unidades a não associados).

Se a cooperativa de trabalho contrata um trabalhador para preencher uma vaga surgida inesperadamente (por exemplo, em caso de doença de associado), tal ato será não-cooperativo.

Trazendo essa doutrina para o nosso tema, se uma cooperativa participa de uma licitação com a Administração, estará realizando ato não-cooperativo, que não se enquadrará com os apontados no art. 79. Assim, a cooperativa se iguala, nesse ponto, às sociedades comerciais.

Tudo o que foi dito sobre ato cooperativo reflete-se no campo tributário, como veremos a seguir.

\subsection{Reflexos tributários dos atos cooperativos e atos não-cooperativos}

Ser ato cooperativo ou ato não-cooperativo reflete diretamente na tributação. $O$ artigo 79 faz a ressalva de que o ato cooperativo não é operação de mercado, o que o afasta da incidência do ICMS. ${ }^{41}$ Os atos não-cooperativos devem ser apresentados à tributação, como decorrência da interpretação do artigo 79 , parágrafo único, já citado, e do artigo 87, que possui a seguinte dicção:

"Os resultados das operações das cooperativas com não associados, mencionados nos arts. 85 e 86, serão levados à conta do 'Fundo de Assistência Técnica, Educacional e Social' e serão contabilizados em separado, de molde a permitir cálculo para incidência de tributos."

Com isso, os atos não-cooperativos são tratados pela legislação fiscal como atos comerciais, e tributados normalmente. Assim, fica claro que as diferenças entre as cooperativas e outras sociedades são de ordem interna, societária ou de atuação com os associados, já que, dependendo com quem a cooperativa relaciona-se, o mesmo fato pode ou não ser tributado.

Desta feita, quando uma cooperativa participa de licitação com a Administração Pública, estará praticando ato não-cooperativo, por não ser realizado com associado,

41 Esse é um dos argumentos. Para maiores dados a esse respeito, consulte-se nosso Tributação das Cooperativas. 
ato esse levado à tributação como ato comercial. Por isso, não pode proceder nenhum motivo de ordem tributária, diretamente ligado ao futuro contrato, que vise vedar a participação dessas sociedades nas licitações, posto que a tributação será a mesma para o vencedor, cooperativa ou não.

No campo dos discrímines possíveis para, pelo princípio da igualdade, afastar-se licitantes, não há correlação lógica (nem fáctica) para utilizar-se argumentos de não-tributabilidade por parte das cooperativas, como restou demonstrado quanto à sua participação em certames públicos que visem preparar futuros contratos com a Administração.

\section{2 - Desigualdades tributárias}

Um argumento utilizado (invalidamente, pensamos) para vedar a participação das cooperativas em licitações refere-se à sua isenção tributária. Nada mais inverídico. Conforme explicamos no nosso Tributação das Cooperativas, já citado, as cooperativas não possuem verdadeiras isenções tributárias. Com tais sociedades ocorre, no mais das vezes, casos de não-incidência de impostos, algumas reconhecidas pelas leis fiscais, outra não.

Assim, quando a Lei $n^{\circ} 5.764 / 71$ diz que os atos cooperativos não são operações de mercado, não está determinando uma isenção. Está simplesmente reconhecendo uma não-incidência, que nem precisaria estar prevista em lei. $O$ ato cooperativo não é operação de mercado pela própria sistemática do imposto que tributa tais fatos (ICMS). Mesmo se não houvesse lei prevendo a hipotese (ato cooperativo não é operação de mercado), não poderia haver tributação pelo ICMS.

O mesmo ocorre com relação ao Imposto de Renda. Conforme expusemos em artigo publicado sobre o assunto:

"As sociedades cooperativas são, por definição legal, entidades sem fins lucrativos. Se a cobrança de imposto sobre a renda tem por base de cálculo a obtenção de lucro e as cooperativas não obtém lucro, logo elas não estão sujeitas ao recolhimento de imposto sobre a renda, mesmo que a legislação assim o determine. Seria o mesmo de cobrar imposto sobre produtos industrializados sobre a comercialização de mercadorias, ou sobre a prestação de serviços.

A norma do artigo 69 da Lei $n^{\circ} 9.532 / 97$ é inócua no que diz respeito ao Imposto sobre a Renda, e será sempre que procurar atingir uma virtual isenção tributária que não exista.

Concluindo, é importante sabermos que, genericamente, as cooperativas não possuem isenção nata de tributos, que pode ser alterada pelo legislador, nem imunidade determinada pela Constituição, mas hipóteses de não-incidência da norma tributária, como no caso do Imposto sobre a Renda e outros tributos". ${ }^{42}$

42 A Lei $n^{\circ} 9.532 / 97$ (IR) e as cooperativas. Revista Dialética, n 34, pág. 63 e segs. 
Assim também, em uma de nossas conclusões publicadas no livro Tributação das Cooperativas, apontamos que as cooperativas não recebem nenhum favor fiscal:

"17. Embora a Constituição não determine uma imunidade, nem para o ato cooperativo, nem para as cooperativas, a tributação diferenciada que as alcança não é decorrência de favor fiscal nem de prática extrafiscal. É resultante de disposições constitucionais, que mandam levar em conta as diferenças existentes entre as cooperativas e as demais sociedades". ${ }^{43}$

Com esses argumentos, queremos afastar os pré-conceitos de natureza tributária que pesam contra as cooperativas. Essas sociedades são vítimas do desconhecimento tanto em matéria de Direito Tributário quanto de Direito Cooperativo.

Atentemos para outro judicioso ensinamento de Lúcia Valle Figueiredo:

"Se a Administração exorbitar os requisitos de habilitação, excedendo sua faixa discricionária, estará ilegalmente restringindo a possibilidade de oferta.

Uma vez estabelecidos os critérios desejados para a habilitação, vincula-se a Administração. Tais critérios hão de ser coerentes e justos. A escolha de critérios inidôneos poderá caracterizar o desvio de poder. Necessário, então, que se atente à finalidade da norma" ${ }^{44}$

Não se tratando de isenção, mas de não-incidência, pode a Administração vedar a participação das cooperativas de licitações? Entendemos que falta motivo justo para tal discrímine. Seguindo os ensinamentos sempre ponderados de Lúcia Valle Figueiredo, a Administração estaria, nesse caso, exorbitando os requisitos legais estabelecidos para o certame, podendo caracterizar desvio de poder.

Reafirmando para concluir esse ponto, as cooperativas possuem particularidades que lhes diferenciam das demais sociedades, inclusive diferenças de natureza tributária, porém que não possuem as extensões apontadas pelos leigos no assunto.

Mas voltemos ao Direito Administrativo, nossa preocupação no momento, para continuarmos apresentando nossos pontos de vista.

\section{$V-$ As cooperativas e as licitações}

1 - Reflexos das desigualdades e os requisitos da licitação

Agora que passamos pelas diferenças entre as cooperativas e as sociedades em geral, voltemos ao tema das licitações, trazendo para cá os conhecimentos ali firmados.

43 Tributação das Cooperativas. cit., p. 177.

44 Lúcia Valle Figueiredo, Direito dos Licitantes, cit. p. 50. 
Por tudo o que ficou dito, vemos que, de modo geral, os requisitos de capacitação econômica e técnica em nada podem prejudicar as cooperativas. As cooperativas serão analisadas no certame, nesses requisitos, com os mesmos rigores utilizados para os demais licitantes.

Quanto à capacitação jurídica, o mesmo ocorre. A Administração Pública deverá exigir a comprovação da regularidade jurídica da cooperativa, nos mesmos limites dos demais licitantes: os registros públicos específicos para cada hipótese (cooperativa, sociedade limitada, sociedade anônima, sociedade civil), regular nomeação das pessoas físicas responsáveis pela direção da sociedades, etc.

Não há motivo de ordem jurídica, no campo dos requisitos licitatórios, para vedar a participação de cooperativas.

\section{2 - Reflexos das desigualdades e os princípios da licitação}

Sendo os princípios básicos da licitação o da igualdade, o da moralidade e o da concorrência, consoante Lúcia Valle Figueiredo, ${ }^{45}$ vamos confrontá-los com a participação das cooperativas no certame.

A moralidade é princípio direcionado ao administrador, fugindo do objetivo de nosso trabalho, pelo que não o abordaremos.

A concorrência exige a participação de todos os interessados, que tenham condições para agir como licitantes. Aqui as cooperativas são parte interessada. Mas nosso ponto de questionamento centrou-se na igualdade e nela vamos nos ater, até porque a participação das cooperativas permitirá a livre concorrência, respeitando o princípio.

Dentre as quatro etapas da licitação (1 - abertura, 2 - habilitação, 3 abertura, classificação e julgamento das propostas, 4 - homologação), nosso problema restringe-se à abertura da licitação (um edital que restrinja a participação das cooperativas) e da habilitação (cooperativa não ser habilitada exatamente por ser uma cooperativa).

A igualdade no certame será entre os licitantes frente à Administração, não entre si. O respeito ao princípio exige que a Administração trate todos os licitantes da mesma forma, com isonomia, sem estabelecer privilégios ou perseguições entre os participantes. Se fosse igualdade entre os concorrentes, ${ }^{46}$ quais seriam essas igualdades exigidas? Igualdade de natureza jurídica (apenas sociedades comerciais, não as civis; - ou dentre as comerciais: sociedades anônimas, ou limitadas?), igualdade nos custos de produção, ou no montante do lucro, ou no número de empregados, ou na cor dos olhos dos proprietários, ou na posição do licitante na cadeia produtiva? Seria impossível exigir igualdade material entre os licitantes!

45 Direito dos Licitantes, cit., p. 22.

46 Concorrente utilizado aqui como sinônimo de licitante. 
Imaginemos uma licitação para aquisição de automóveis. Participam as empresas A, B e C. A primeira delas localiza-se a 500 quilômetros da sede da entidade licitante. A segunda localiza-se a 150 quilômetros e a terceira a 1.200 quilômetros. Como todas elas terão gastos com transportes, seguramente a B levará vantagem. O mesmo pode ocorrer com o custo salarial entre as três, ou o fato de que uma delas possui empréstimos subsidiados no BNDES e as outras não (com isso uma economiza em um lado, tornando seu produto mais vantajoso).

Outras sociedades podem ter mais vantagens que as cooperativas. Uma empresa privatizada, que tenha endividamento subsidiado pelo Governo Federal, através do BNDES, tem mais benefícios que as empresas do setor que já eram privadas, cujo endividamento não era objeto de linha de crédito subsidiado ${ }^{47}$ Têm muito mais vantagens que as cooperativas.

Vamos apresentar outros exemplos para ilustrar nossos pontos de vista. Uma licitação para fornecimento de material de escritório (papel, canetas, tintas para impressoras). Participam da licitação (oferecem proposta) uma cooperativa e uma empresa comercial. A cooperativa é do tipo de compra em comum (assemelha-se a uma papelaria, muito comum em universidades), e a empresa comercial é uma papelaria. Várias diferenças entre elas existem: os proprietários das cooperativas são muitos (no mínimo vinte), enquanto os sócios da cooperativa podem ser apenas dois. Esta diferença é relevante para o processo licitatório? Não. E quanto à tributação, aspecto de especial relevo para aqueles que entendem pela não participação das cooperativas em licitações? Por ser ato não-cooperativo, a operação porventura realizada será oferecida à tributação normalmente. Não haverá diferença em termos tributários.

Uma empresa verticalizada, que preencha mais níveis da escala produtiva do que o normal, pode ser diferente, para fins de licitação? Por ela possuir seu próprio banco, tem o dinheiro de terceiros a um custo mais baixo e por isso é diferente?

Outra questão: licitação para aquisição de alimentos. Participam um produtor rural, um supermercado e uma cooperativa. Perguntamos: haverá diferença entre eles que justifique a exclusão de algum deles? Cremos que não.

Se a Administração vai licitar a contratação de prestador de serviço de limpeza (serviço terceirizado), por exemplo, é irrelevante no contrato constar quantos proprietários tem a empresa, ou mesmo quantas pessoas decidem seus rumos (não em nível de diretoria, mas de donos). Desta forma, as cooperativas poderão participar de licitações. Caso contrário (somente para fins de entendimento, já que não há correlação lógica entre o discrímine e o móvel — o objeto - do contrato), uma S/A não poderia, como também não uma cooperativa, participar do certame.

Com isso, as particularidades das cooperativas (administração democrática, juros limitados sobre o capital, retorno das sobras...) não podem ser objeto de

47 De se notar que no processo de privatização em curso, algumas sociedades foram arrematadas por, apenas, cerca de vinte por cento do seu valor em desemboiso de moeda corrente. $O$ restante foi motivo de linha de crédito especial, subsidiado, portanto, e pela aceitação de títulos de mercado, adquiridos por valores muito abaixo do exposto em face (o valor de face foi o aceito pelo Governo). A privatização da Eletropaulo Metropolitana é exemplo suficiente. 
discriminação, por fugirem totalmente do interesse da Administração quando esta vai contratar com pessoas jurídicas.

Uma licitação pode barrar a entrada de sociedades limitadas, ou sociedades anônimas? Em se tratando de aplicação do princípio da igualdade, temos que responder que depende, na esteira de Celso Antônio Bandeira de Mello. ${ }^{48}$ Depende de haver correlação lógica entre o discrímine e o motivo da discriminação. Há uma correlação lógica entre um eventual discrímine (não participação das cooperativas em licitações) e o motivo discriminante (cooperativas não são iguais às demais sociedades)? Genericamente, contudo, a resposta é não.

Como apontado pelos doutrinadores (dentre eles José Afonso da Silva), a igualdade na licitação é de tratamento. É uma igualdade de postura da Administração frente aos licitantes. Isso significa que a Administração não poderá conceder tratamento diferenciado para nenhum dos licitantes, beneficiando uns ou perseguindo outros. Em nenhum momento, há no Direito Positivo ou na Ciência do Direito, determinação que autorize supor que o princípio da igualdade está a exigir licitantes iguais.

Nesse ponto, há aplicação do princípio da igualdade formal, visto no item II.1; não há elementos para se supor tratar-se de igualdade substancial ou material, nem mesmo uma mitigação entre um e outro (igualdade jurídica proporcional). É a igualdade na lei (item II.2), destinada aos elaboradores e aos aplicadores das normas, não uma mera igualdade perante a lei.

\section{$V I-$ Conclusões}

O problema colocado na introdução foi: podem as cooperativas participar das licitações públicas? $O$ que respeita o princípio da igualdade na licitação: a possibilidade de participação ou de não participação dessas sociedades no certame?

Nossas conclusões são as seguintes:

1. Dentre as doutrinas da igualdade substancial, formal e jurídica proporcional, a aplicada à licitação é a formal, que determina igual tratamento jurídico dos licitantes. O princípio será atendido se houver isonomia de oportunidade para os interessados em participar do certame.

2. A igualdade perante a lei significa, em última análise, respeito ao princípio da legalidade. A isonomia de nosso Texto Constitucional significa igualdade na lei. Com isso, o princípio é primeiramente direcionado para o legislador, que não pode produzir leis que tragam desarmonia à igualdade de tratamento, exceto se houver correlação lógica entre o discrímine e o motivo da discriminação.

3. O princípio da igualdade aplicado na licitação é o mesmo princípio geral de Direito. Não há um princípio da igualdade específico, diferente dos demais, só para a licitação. Sendo assim, não há separação doutrinária entre os seus elementos, naquilo que sejam incidentes ao caso concreto. 
4. As particularidades das sociedades cooperativas são mais de natureza interna, societária, não sendo significativas para a Administração Pública, para fins de licitação.

5. Quando as cooperativas transacionam com a Administração Pública, praticam atos não-cooperativos, não protegidos por regras próprias. Inclusive, a tributação aplicável passa a ser a mesma das sociedades comerciais.

6. Não há motivo jurídico que permita a segregação das cooperativas dos processos licitatórios, de maneira geral. A vedação de participação dessas sociedades exige comprovação fáctica da correlação lógica analisada em cada caso particularmente.

7. Alijar as cooperativas das licitações fere o princípio da igualdade. Se uma sociedade for excluída de uma licitação por ser cooperativa, estará havendo restrição ilegal, ou aplicação de um critério injusto (portanto desigual, na esteira do afirmado por Bobbio). Lembremo-nos, por oportuno, que inclusive não desigualar pode ferir justamente o princípio da igualdade.

8. Participando de licitação pública, a cooperativa não levará nenhuma vantagem financeira para seus associados já que os resultados serão contabilizados no FATES (fundo indivisível), não podendo ser distribuído entre os sócios nem se a cooperativa for fechada.

\section{VII - Bibliografia}

BECHO, Renato Lopes. Tributação das Cooperativas. 1. ed. São Paulo: Dialética, 1998. $191 \mathrm{p}$.

. "O Princípio da Igualdade no Direito Administrativo", in Princípios Informadores do Direito Administrativo. 1. ed. São Paulo: NDJ, 1997. 271 p.

"A Lei no 9.532/97 (IR) e as cooperativas. Revista Dialética. São Paulo: Dialética, 1998.

BOBBIO, Norberto. Igualdade e Liberdade. Tradução de Carlos Nelson Coutinho. 2. ed. Rio de Janeiro: Ediouro, 1997. 96 p.

CANOTILHO, J. J. Gomes. Direito Constitucional e Teoria da Constituição. Coimbra: Almedina, 1998. $1.352 \mathrm{p}$.

DI PIETRO, Maria Sylvia Zanella. Direito Administrativo. 8. ed. São Paulo: Atlas, 1997. $566 \mathrm{p}$.

FIGUEIREDO, Lúcia Valle. Direito dos Licitantes. 4. ed. rev. e ampl. São Paulo: Malheiros, 1994. $136 \mathrm{p}$.

Curso de Direito Administrativo. 3. ed. rev. e atual. São Paulo: Malheiros, 1998. $585 \mathrm{p}$.

LEAL, Víctor Nunes. Problemas de Direito Público. Rio de Janeiro: Forense, 1960. $482 \mathrm{p}$.

MEIRELLES, Hely Lopes. Direito Administrativo Brasileiro. 19. ed. atual. São Paulo: Revista dos Tribunais, 1994. 702 p. 
MELLO, Celso Antônio Bandeira de. Licitação. 1. ed. São Paulo: Revista dos Tribunais, $1985.177 \mathrm{p}$.

O Conteúdo Jurídico do Princípio da Igualdade. 3. ed. São Paulo: Melhoramentos, 1993. $48 \mathrm{p}$.

MIRANDA, Pontes de. Tratado de Direito Privado. Parte especial tomo XLIX. Rio de Janeiro: Borsoi, 1965.

SILVA, José Afonso da. Curso de Direito Constitucional Positivo. 9. ed. São Paulo: Melhoramentos, 1993. $768 \mathrm{p}$.

MEIRELLES TEIXEIRA, José Horácio. Curso de Direito Constitucional. Org. $e$ atual. por Maria Garcia. Rio de Janeiro: Forense Universitária, 1991. 785 p. 


\section{Revista de Direito Administrativo}

\section{Caio Tácito (organizador)}

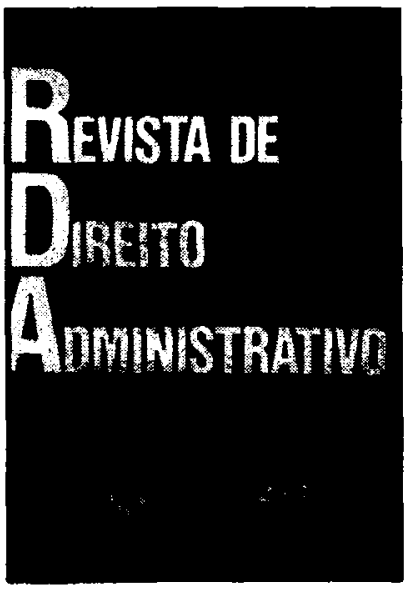

Com mais de meio século de publicação regular e ininterrupta, é a mais completa publicação no gênero. Em quatro números anuais oferece a mais completa e atualizada visão do Direito Administrativo brasileiro, no plano da doutrina e pareceres, da jurisprudência administrativa, judicial e do Tribunal de Contas da Uniāo, e da Legislaçāo Federal. Na sua especialidade, divulga temas de Direito Constitucional, Tributário ou Processual que interessam à interpretação e aplicação dos princípios e normas que regulam a atividade da Administração Pública Direta e Indireta.

Brochura Form. 16x23

Criada em 1945

\section{Revista de Direito Administrativo Seleção Histórica}

Vários autores

A presente coletânea reúne trabalhos publicados nos 150 primeiros números da Revista de Direito Administrativo, os quais, pela densidade do conteúdo, permanecem válidos como subsídios à doutrina do Direito Público. A seleção, se não esgota o lastro do passado, evidencia a perenidade de contribuiçōes antigas e propicia aos leitores de agora uma expressiva amostra da presença de autores falecidos que deixaram marca na história da ciência jurídica nacional.

Ref. 0102

Form. 16x23
Brochura 1996
467 págs.

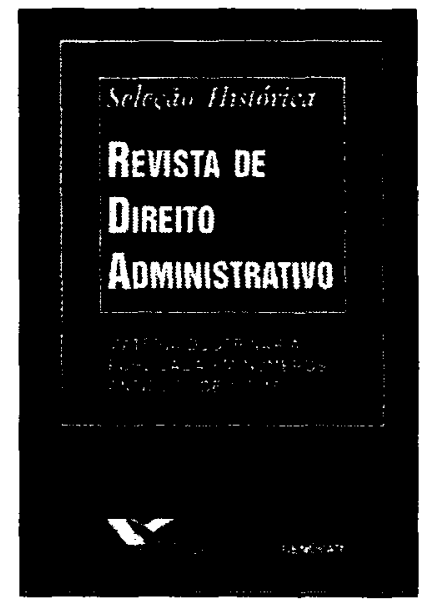

